\title{
Employment, Work Productivity, and Biologic Treatments in Self-Reported Axial Spondyloarthritis: a Cross-Sectional Study in a Female Predominant Population from the ArthritisPower Registry
}

\author{
Kelly Gavigan (D) - W. Benjamin Nowell · Theresa Hunter • \\ Jeffrey R. Curtis · William N. Malatestinic · Rebecca J. Bolce • \\ Jeffrey R. Lisse · Jessica Walsh
}

Received: October 27, 2021 / Accepted: January 31, 2022 / Published online: February 21, 2022

(C) The Author(s) 2022

\begin{abstract}
Introduction: The aim of this study was to characterize employment, work productivity, and biologic disease-modifying anti-rheumatic drug (bDMARD) treatment in a predominantly female population of axial spondyloarthritis (axSpA) patients in a real-world setting.

Methods: This was a cross-sectional study of axSpA participants within the ArthritisPower registry. Outcomes were assessed with surveys (Work Productivity and Activity Impairment [WPAI], Bath Ankylosing Spondylitis Disease Activity Index [BASDAI], and Patient-Reported Outcomes Measurement Information System instruments) and compared between subgroups
\end{abstract}

Supplementary Information The online version contains supplementary material available at https:// doi.org/10.1007/s40744-022-00428-x.

K. Gavigan $(\bowtie) \cdot$ W. B. Nowell

Global Healthy Living Foundation, 515 N Midland

Ave, Upper Nyack, NY 10960, USA

e-mail: kgavigan@ghlf.org

T. Hunter - W. N. Malatestinic - R. J. Bolce

J. R. Lisse

Eli Lilly and Company, Indianapolis, IN, USA

J. R. Curtis

University of Alabama at Birmingham, Birmingham, AL, USA

J. Walsh

University of Utah, Salt Lake City, UT, USA (employed vs. not employed; taking vs. not taking a bDMARD).

Results: Among the 195 participants, 117 (60.0\%) were employed and 78 (40.0\%) were not employed entirely or partially due to axSpA. The mean age of the participants was 47.6 years and $86.7 \%$ were female. Current bDMARD use was reported by $57.4 \%$ of those surveyed (59.8\% employed vs. $53.9 \%$ not employed; $p=0.408$ ). Compared to not employed participants, employed participants had more favorable disease activity (BASDAI 6.0 vs. $7.6 ; p<0.001$ ) and overall health (self-rated health 2.5 vs. 1.8; $p<0.001)$. Employed participants, compared to not employed participants, were diagnosed at an earlier age (36.0 vs. 42.5 years, respectively) and experienced a shorter time between symptom onset and diagnosis (9.5 vs. 13.6 years, respectively). Employed participants reported missing on average 6.5 days of work and experienced a $52.7 \%$ impairment on work productivity due to axSpA over a 3-month period. Absenteeism and presenteeism were statistically similar between participants taking a bDMARD versus those not taking a bDMARD.

Conclusions: Although bDMARD treatment rates were similar between employed and not employed participants, disease activity and overall health were better in employed than non-employed participants. Employed participants experienced substantial work productivity impairment due to axSpA. 
Keywords: Axial spondyloarthritis; Ankylosing spondylitis; Work productivity; Employment; Female population

\section{Key Summary Points}

Why carry out this study?

An estimated $0.9 \%-1.4 \%$ of the adult population in the USA has axial spondyloarthritis (axSpA), a chronic and inflammatory rheumatic disease that negatively impacts function.

The burden of axSpA and the early age of symptom onset make workforce participation a particularly relevant issue with this patient population.

The aim of this study was to characterize work productivity and employment outcomes among participants on a biologic disease-modifying anti-rheumatic drug (bMARD) versus those not on a bDMARD in a predominantly female patient population.

\section{What was learned from the study?}

The study found that not employed participants experienced a significantly longer time interval between symptom onset and axSpA diagnosis, and employed participants reported frequent challenges with absenteeism that they largely attributed to axSpA.

Compared to not employed participants, employed participants had more favorable disease activity and overall health.

The participants on a bDMARD who were employed had better health outcomes for all measures than participants on a bDMARD who were not employed, suggesting that patients' symptom management may play a significant role in work productivity and employment retention.

\section{INTRODUCTION}

An estimated $0.9-1.4 \%$ of the adult population in the USA has axial spondyloarthritis (axSpA), a chronic and inflammatory rheumatic disease $[1,2]$. The condition includes non-radiographic axSpA and ankylosing spondylitis and most commonly presents in patients before the age of 40 years $[3,4]$. Patients with axSpA experience symptoms that negatively impact function, including inflammatory back pain, arthritis, enthesitis, and dactylitis [5]. The burden of axSpA and the early age of symptom onset make workforce participation a particularly relevant issue with this patient population. Previous studies have found that, compared to the general population, employment among axSpA patients was slightly decreased and partial work disability was substantially higher [6-8]. After adjusting for age and sex, the risk of people with axSpA leaving the workforce has been demonstrated to be 3.1-fold higher than in the general population [6]. Additionally, axSpA is associated with decreased work productivity, absenteeism, and presenteeism compared to the general population [9-11]. The total individual and societal cost of axSpA is dominated by work disability, with decreased physical function and increased disease activity both associated with a significantly increased cost per patient $[12,13]$. Previous studies have also analyzed the correlation between the initiation of treatment with a biologic disease-modifying anti-rheumatic drug (bDMARD) and work productivity [14-18], with clinical trials and observational studies finding that treatment with bDMARDs improves work productivity and activity impairment among patients with axSpA [19-22].

Although axSpA has been historically considered to be a predominantly male disease, recent data indicate similar prevalence between males and females [23, 24]. However, women and men experience axSpA differently, with women reporting higher disease burden and less responsiveness to treatment [25-27]. Despite the growing recognition that axSpA is different in women than men, women continue to be widely under-studied in axSpA research, 
including studies assessing employment and work productivity.

The goal of this study was to characterize employment, work productivity, and bDMARD treatment in a predominantly female population of axSpA patients in a real-world setting. Specifically, we aimed to characterize work productivity and employment outcomes among participants on a bDMARD versus those not on a bDMARD.

\section{METHODS}

\section{Study Design and Participants}

This was an observational, cross-sectional study. Participants were recruited from the ArthritisPower research registry, an online registry for patients with rheumatic and musculoskeletal disease. ArthritisPower was initially founded as a collaboration between the non-profit Global Healthy Living Foundation and rheumatology researchers at the University of Alabama at Birmingham. Launched in 2015, ArthritisPower comprises members with a self-reported rheumatic and musculoskeletal disease diagnosis who provide explicit consent to participate in and provide cross-sectional or longitudinal data for research studies like the present study $[28,29]$. Participants in the ArthritisPower registry are predominantly female, with $88 \%$ of the $>32,000$ participants in the USA reporting as female.

Members of the ArthritisPower registry who were residents of the USA and aged $\geq 19$ years ( $\geq 21$ for residents of Puerto Rico) with a selfreported rheumatologist diagnosis of axSpA were eligible to participate in this study. An email invitation with a survey link was sent to eligible ArthritisPower members from November 2019 to March 2020. Unique links were used to ensure that members could not take the survey twice. Follow-up reminder emails were sent to members who had not clicked on the initial invitation. This study has received an exempt determination from the Advarra Institutional Review Board (\#Pro00039559), stating that the study is exempt from Institutional
Review Board oversight. This study was performed in accordance with the Helsinki Declaration of 1964, and its later amendments. All subjects provide informed consent to participate in the study.

\section{Survey}

Eligible participants completed an 81-item survey developed in partnership with patient research partners and rheumatologists. The goal of the survey was to better understand how the treatment and disease management strategies of axSpA patients impact their symptoms and subsequent employment status and work productivity. Participants reported their disease activity (Bath Ankylosing Spondylitis Disease Activity Index [BASDAI] [30]; 0-10 scale, with a $\geq 4$ indicating suboptimal disease control), patient-reported outcomes using the computer adapted testing versions of the NIH PROMIS measures [31] for pain interference, physical function, and sleep disturbance (0-100 scale), and one-item PROMIS measures for self-rated health and depression (0 [poor] to 5 [excellent] scale). Participants then answered a number of questions on inflammatory back pain characteristics: (1) Have you ever had back or buttock pain for 3 or more months continuously? (2) How old were you when this back or buttock pain lasting 3 or more months began? (3) Have you ever been told that you have sacroiliitis (inflammation in the joints that connect your tailbone [lower back] to your pelvis [hips])? (4) Has your back or buttock pain come on gradually over time (over days, weeks, or months)? (5) Has your back or buttock pain usually felt better with exercise? (6) Has your back or buttock pain mostly occurred at night? (7) Has your back or buttock pain mostly felt better after getting up for the day? [32].

In addition, participants reported on their axSpA symptom history and family history with axSpA; current and previous axSpA treatment and disease management strategies; treatment decision-making and journey; experience with bDMARDs (if reported being ever treated with bDMARDs), and impact of axSpA symptoms on work and productivity, including the Work 
Productivity and Activity Impairment (WPAI) questionnaire [33]. The WPAI questionnaire is made up of three parts: work days missed (absenteeism) due to axSpA, percentage impairment while working due to axSpA (presenteeism), and percentage impairment on activities other than work (activity impairment) due to axSpA. Participants who reported not being employed (stay-at-home parent/homemaker; on sick leave, worker's compensation leave or other leave; unemployed; retired; disabled; other) were asked if the primary reason they were not employed was partially due to axSpA, entirely due to axSpA, due to other health issues, or for reasons not related to health. Participants who reported being not employed due to a reason other than axSpA were removed from the analysis. The survey was programmed using Health Insurance Portability and Accountability Act (HIPAA)-compliant SurveyMonkey software.

\section{Statistical Analysis}

Data were summarized descriptively: categorical variables were analyzed by frequency counts and percentages; continuous variables were analyzed by mean (standard deviation [SD]), minimum and maximum. Chi-square and analysis of variance tests were used to determine significant differences in demographic characteristics by employment status and gender, and to determine significant differences in employment absenteeism, presenteeism, and activity impairment by treatment (bDMARD use vs. no bDMARD use). Binary logistic regression analysis was conducted to assess the factors associated with employment. Significance was determined at an alpha of 0.05. Results of respondents who did not complete the survey were removed prior to analysis. All analyses were performed using SAS version 9.4 software (SAS Institute, Cary, NC, USA).

\section{RESULTS}

\section{Population and Baseline Characteristics}

A total of 2727 ArthritisPower members who self-reported an axSpA diagnosis were sent an invitation email to participate in this study, $87 \%$ of whom were female. Of those invited, $48.4 \%(1321 / 2727)$ opened the email and, of the people who opened the invite email, 29.3\% (387/1321) clicked the link to take the survey. Among members who clicked the email invitation, $274(70.8 \%)$ qualified for and completed the survey. Of the 274 survey participants, 49 $(17.9 \%)$ reported their axSpA diagnosis was not made or confirmed by a rheumatologist and were removed from the analysis. Of the remaining 225 participants, 108 participants $(48.0 \%)$ reported being not employed, of whom $78(72.2 \%)$ reported not being employed either partially or entirely because of their axSpA; the remaining $30(27.8 \%)$ reported not being employed due to reasons other than their axSpA and were removed from the analysis. This resulted in a total of 195 (71.2\%) participants who satisfied the criteria for being included in this analysis (Fig. 1). Characteristics of the 30 participants who were not employed for reasons other than axSpA can be found in Electronic Supplementary Material (ESM) Table S1.

The majority of the 195 participants were female $(169,86.7 \%)$ and White $(167,85.6 \%)$, with a mean (SD) age of 47.6 (10.6) years (Table 1). Participants' comorbidities included fibromyalgia (84, 43.1\%), osteoarthritis (80, $41.0 \%)$, and herniated disk or degenerative disk disease (DDD) $(78,40.0 \%)$. The majority of participants $(154,79.0 \%)$ were currently being treated with a bDMARD or had been in the past, and $112(57.4 \%)$ were on a bDMARD at the time of the study. A total of $171(87.7 \%)$ participants had ever been on a DMARD, including biologic and conventional synthetic DMARDs. All participants reported at least one axSpA manifestation (Table 1) currently or in the past, and participants reported 'yes' to a mean of 4.0 (SD 1.2) out of the seven characteristics of inflammatory back pain. Participants on average scored in the high disease activity range for the 


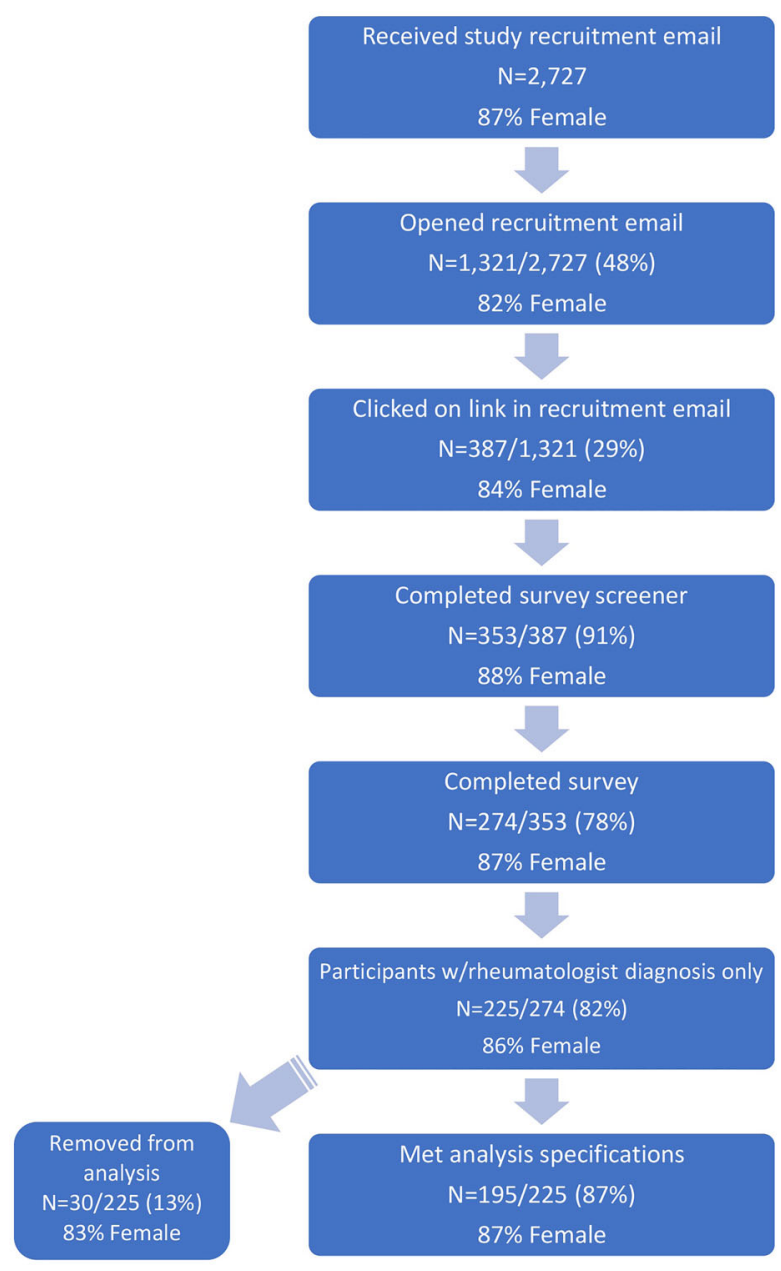

Fig. 1 Flow diagram of participation in the study

BASDAI measure (6.6 [SD 1.9]) and reported poor self-rated health (2.2 [0.9]) and high emotional distress (2.5 [0.9]). On average, participants also reported moderate pain interference (65.8 [6.2]), physical function (36.6 [6.4]), and sleep disturbance (60.6 [8.2]) (Table 1).

Demographic and clinical characteristics between female and male participants were similar, but with some notable differences. The male participants $(n=26)$ were significantly older (mean [SD] 52.3 [11.6]) than the female participants $(n=169 ; 46.9$ [10.3]; $p=0.014)$ (Table 1). More male participants than female ones had a college degree or higher (20 [76.9\%] vs. $81[47.9 \%] ; p=0.006)$. While not significant, the duration in years between symptom onset and diagnosis by a physician was shorter among male participants (8.5 [8.6]) than among female participants (11.6 [11.7]; $p=0.200)$. Compared to male participants, female participants more often reported having fibromyalgia (47.3\% vs. $15.4 \% ; p=0.002)$, heel enthesitis (78.7\% vs. $53.9 \%$, respectively; $p=0.006$ ), and dactylitis (52.1\% vs. $30.8 \%$; $p=0.043)$ (Table 1$)$.

\section{Employment}

At the time of the study, 117 (60.0\%) participants were employed and 78 (40.0\%) were not employed for reasons either partially or fully due to their axSpA, with $59.8 \%(n=70)$ of employed participants on a bDMARD compared to $53.9 \%(n=42)$ of participants who were not employed $(p=0.131)$. Employed participants had a significantly younger average [SD] age of initial axSpA diagnosis (36.0 [11.0] years) than not employed participants (42.5 [10.4]; $p<0.001)$, despite having a comparable average age of symptom onset (26.5 [10.8] vs. 28.8 [14.2]; $p=0.206)$. As such, not employed participants experienced on average a significantly longer length of time in years between symptom onset and diagnosis (13.6 [14.1] vs. 9.5 [8.9]; $p=0.012$ ).

Differences in patient reported outcome (PRO) scores between employed participants and not employed participants were significant for all outcomes observed, with not employed participants having significantly worse outcomes than their employed counterparts for all measures: BASDAI (7.6 [SD 1.5] vs. 6.0 [1.8]; $p<0.001)$, pain interference (68.8 [4.7] vs. 63.9 [6.3]; $p<0.001)$, physical function (32.7 [4.6] vs. 39.2 [6.2]; $p<0.001)$, sleep disturbance (63.7 [7.1] vs. 58.6 [8.2]; $p<0.001)$, self-rated health (1.8 [0.7] vs. $2.5[0.9] ; p<0.001)$, and emotional distress (2.3 [0.8] vs. 2.6 [0.9]; $p=0.024)$. Additionally, not employed participants more frequently reported concomitant diagnoses of fibromyalgia $(60.3 \%$ vs. $31.6 \% ; p<0.001)$, osteoarthritis $(55.1 \%$ vs. $31.6 \% ; p<0.001)$, herniated disk or DDD $(57.7 \%$ vs. $28.2 \%$; $p<0.001)$, or spinal stenosis $(39.7 \%$ vs. $18.0 \%$; $p<0.001$ ) (Table 1).

Among participants on a bDMARD, the differences in PRO scores between employed 


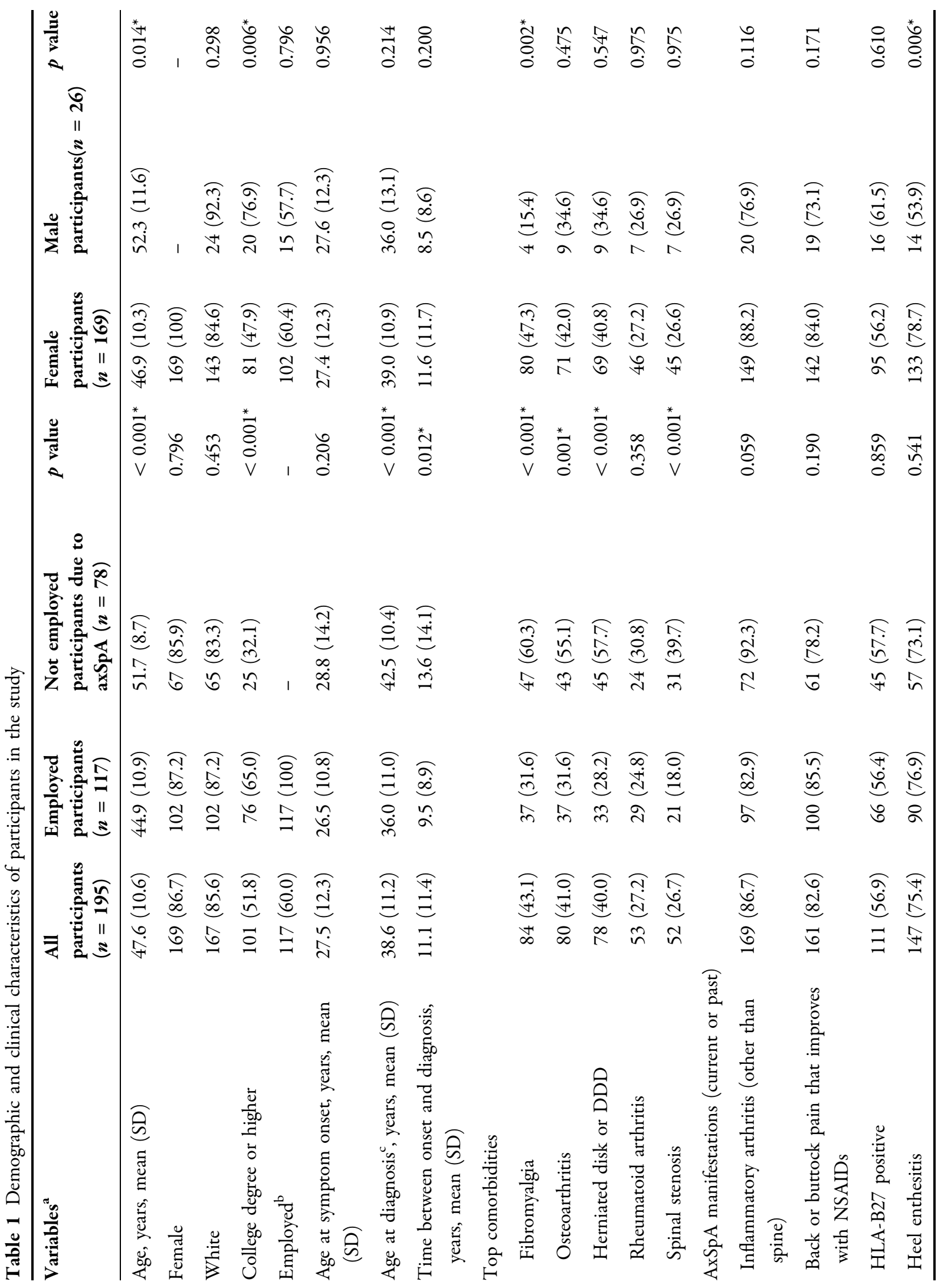




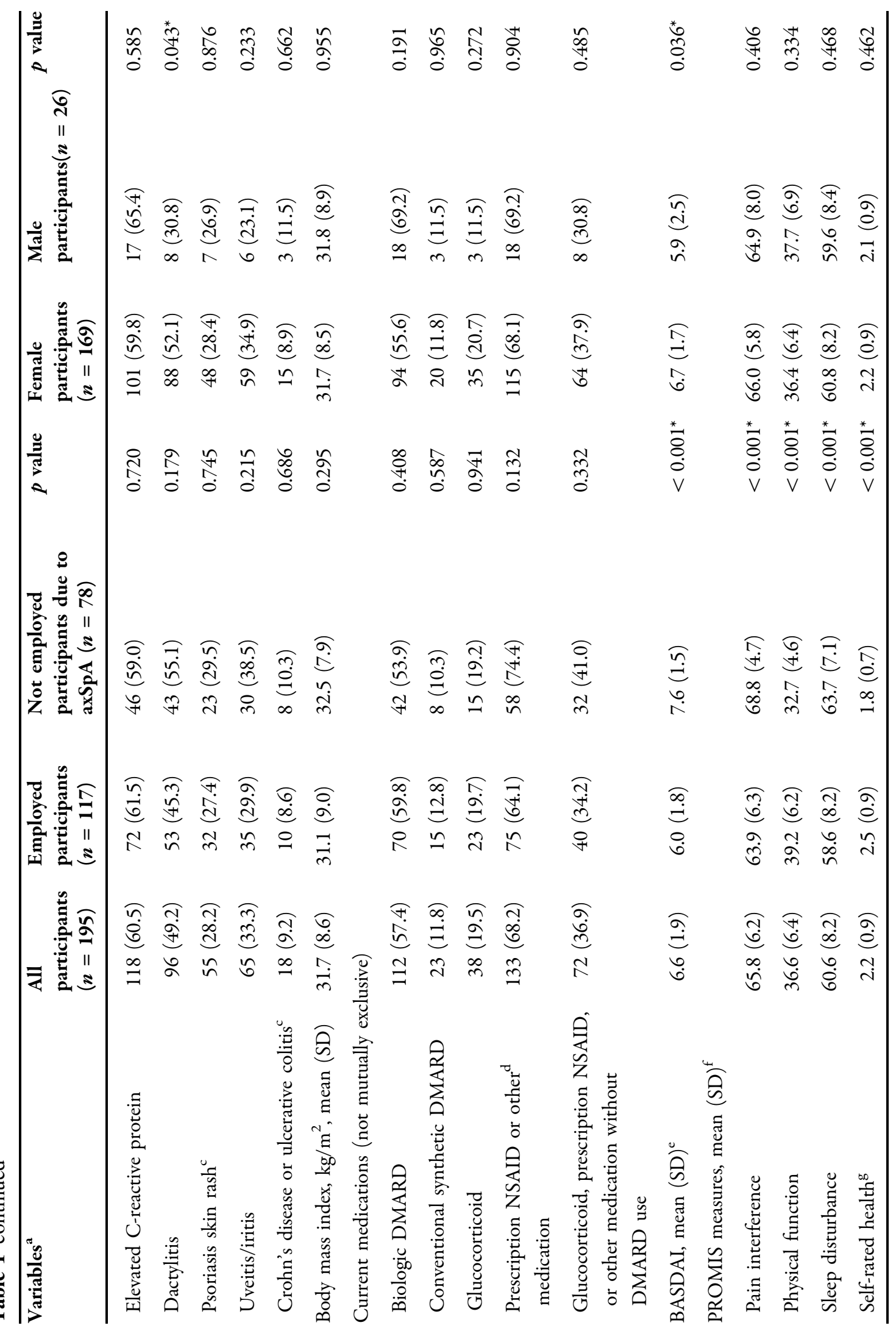




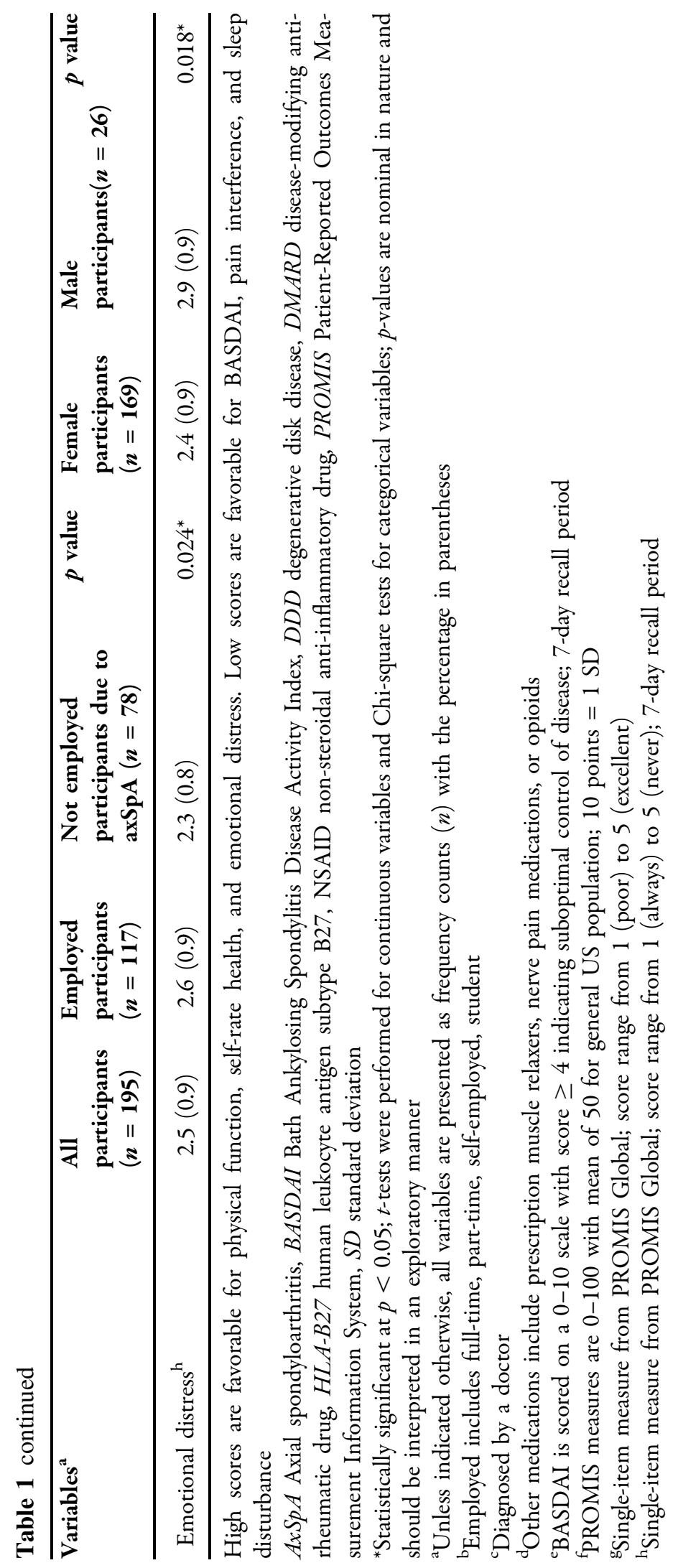


Table 2 Health state and disease activity in employed and not employed participants, according to axSpA treatment

\begin{tabular}{|c|c|c|c|c|c|c|}
\hline \multirow[t]{2}{*}{ Measures } & \multicolumn{3}{|c|}{ Biologic $(n=112)$} & \multicolumn{3}{|c|}{ No biologic $(n=83)$} \\
\hline & $\begin{array}{l}\text { Employed } \\
(n=70)\end{array}$ & $\begin{array}{l}\text { Not employed } \\
(n=42)\end{array}$ & $p$ value & $\begin{array}{l}\text { Employed } \\
(n=47)\end{array}$ & $\begin{array}{l}\text { Not employed } \\
(n=36)\end{array}$ & $p$ value \\
\hline $\begin{array}{l}\text { BASDAI, mean } \\
(\mathrm{SD})^{\mathrm{a}}\end{array}$ & $5.7(1.6)$ & $7.5(1.7)$ & $<0.001^{*}$ & $6.4(2.0)$ & $7.7(1.4)$ & 0.003 \\
\hline \multicolumn{7}{|c|}{ PROMIS measures, mean (SD) ${ }^{\mathrm{b}}$} \\
\hline Pain interference & $62.8(5.2)$ & $69.5(4.1)$ & $<0.001^{*}$ & $65.4(7.3)$ & $68.0(5.2)$ & 0.073 \\
\hline Physical function & $39.5(5.1)$ & $32.3(3.8)$ & $<0.001^{*}$ & $38.6(7.6)$ & $33.0(5.4)$ & $<0.001^{*}$ \\
\hline Sleep disturbance & $57.1(7.8)$ & $64.2(7.3)$ & $<0.001^{*}$ & $60.8(8.4)$ & $63.1(7.0)$ & 0.181 \\
\hline Self-rated health ${ }^{c}$ & $2.4(0.8)$ & $1.7(0.7)$ & $<0.001^{*}$ & $2.6(0.9)$ & $1.9(0.8)$ & $<0.001^{*}$ \\
\hline $\begin{array}{l}\text { Emotional } \\
\text { distress }^{\mathrm{d}}\end{array}$ & $2.8(0.9)$ & $2.3(0.8)$ & $0.012^{*}$ & $2.4(0.9)$ & $2.3(0.9)$ & 0.692 \\
\hline
\end{tabular}

High scores are favorable for physical function, self-rate health, and emotional distress. Low scores are favorable for BASDAI, pain interference, and sleep disturbance

${ }^{*}$ Statistically significant at $p<0.05$; $t$-tests were performed for continuous variables. $p$-values are nominal in nature and should be interpreted in an exploratory manner

${ }^{a}$ BASDAI is scored on a $0-10$ scale with score $\geq 4$ indicating suboptimal control of disease; 7 -day recall period

${ }^{b}$ PROMIS measures are 0-100 with mean of 50 for general US population; 10 points $=1 \mathrm{SD}$

${ }^{\mathrm{c}}$ Single-item measure from PROMIS Global; score range from 1 (poor) to 5 (excellent)

${ }^{\mathrm{d}}$ Single-item measure from PROMIS Global; score range from 1 (always) to 5 (never); 7-day recall period

participants and not employed participants were also significant (Table 2). Compared to employed participants on a bDMARD, not employed participants on a bDMARD had significantly worse health outcomes for all measures: BASDAI (5.7 [SD 1.6] vs. 7.5 [1.7]; $p<0.001)$, pain interference (62.8 [5.2] vs. 69.5 [4.1]; $p<0.001)$, physical function (39.5 [5.1] vs. 32.3 [3.8]; $p<0.001)$, sleep disturbance (57.1 [7.8] vs. 64.2 [7.3]; $p<0.001)$, self-rated health (2.4 [0.8] vs. $1.7[0.7] ; p<0.001)$, and emotional distress (2.8 [0.9] vs. 2.3 [0.8]; $p=0.012)$. Among participants not on a bDMARD, not employed participants reported significantly worse health outcomes than employed participants for the BASDAI measure (7.7 [1.4] vs. 6.4 [2.0]; $p=0.003)$, physical function (33.0 [5.4] vs. $38.6[7.6] ; p<0.001)$, and self-rated health (1.9 [0.8] vs. 2.6 [0.9]; $p<0.001)$.

We conducted a logistic regression analysis to assess the variables associated with employment (ESM Table S2). Education, younger age, and younger age at diagnosis were statistically significant, with a positive correlation with employment (education: $p<0.001$; age: $p=0.022$; younger age at diagnosis: $p=0.033$ ).

\section{Work Impairment}

Employed participants $(n=117)$ reported a mean (SD) of 6.5 (9.2) workdays lost due to absenteeism over a 3-month period. Participants missed the highest number of days due to their axSpA symptoms (mean [SD] 5.0 [7.1]) compared to other axSpA-related reasons, such as doctors' appointments (1.4 [2.2]) and treatment side-effects (0.8 [2.3]). On average, employed participants reported their axSpA contributed to a $52.7 \%$ impairment of their work productivity (SD 22.2\%) and a 59.2\% impairment of their ability to do regular daily activities (SD 20.7\%) over the prior 3 months. Workdays missed due to absenteeism and impact on productivity and daily activity were comparable between participants on a bDMARD 
Table 3 Absenteeism, presenteeism, and activity impairment by axSpA treatment

\begin{tabular}{|c|c|c|c|c|}
\hline Employed participants & $\begin{array}{l}\text { All } \\
\text { participants } \\
(n=117)\end{array}$ & $\begin{array}{l}\text { Participants on a } \\
\text { bDMARD } \\
(n=70)\end{array}$ & $\begin{array}{l}\text { Participants not on } \\
\text { bDMARD }(n=47)\end{array}$ & $p$ value \\
\hline \multicolumn{5}{|c|}{ Work Productivity and Activity Impairment questionnaire, mean $(\mathrm{SD})^{\mathrm{a}}$} \\
\hline WPAI: absenteeism ${ }^{\mathrm{b}}$ & $6.5(9.2)$ & $6.7(9.7)$ & $6.3(8.5)$ & 0.822 \\
\hline WPAI: presenteeism ${ }^{c}$ & $52.7(22.2)$ & $51.4(21.6)$ & $54.7(23.3)$ & 0.440 \\
\hline WPAI: activity impairment ${ }^{\mathrm{d}}$ & $59.2(20.7)$ & $58.0(19.2)$ & $61.1(22.9)$ & 0.435 \\
\hline \multicolumn{5}{|c|}{ Missed work/school in the past 3 months due to axSpA } \\
\hline $\begin{array}{l}\text { Reported missing work/school due to axSpA, } \\
n(\%)\end{array}$ & $88(75.2)$ & $49(70.0)$ & $39(83.0)$ & 0.111 \\
\hline $\begin{array}{l}\text { Days missed due to axSpA (any reason), mean } \\
(\mathrm{SD})^{\mathrm{e}}\end{array}$ & $6.5(9.2)$ & $6.7(9.7)$ & $6.3(8.5)$ & 0.822 \\
\hline Days missed due to axSpA symptoms & $5.0(7.1)$ & $4.9(7.1)$ & $5.2(7.2)$ & 0.829 \\
\hline $\begin{array}{l}\text { Days missed due to an infection and/or illness } \\
\text { resulting from my axSpA }\end{array}$ & $1.0(2.7)$ & $1.5(3.5)$ & $0.3(0.7)$ & $0.039^{*}$ \\
\hline $\begin{array}{l}\text { Days missed due to a doctor's appointment } \\
\text { (e.g., for an infusion/injection or check-in) }\end{array}$ & $1.4(2.2)$ & $1.8(2.7)$ & $0.8(1.2)$ & $0.026^{*}$ \\
\hline $\begin{array}{l}\text { Days missed due to side effect(s) from my } \\
\text { treatment for my axSpA }\end{array}$ & $0.8(2.3)$ & $1.2(3.0)$ & $0.2(0.5)$ & $0.029^{*}$ \\
\hline $\begin{array}{l}\text { Days missed for other reason relating to } \\
\text { axSpA }\end{array}$ & $1.0(5.2)$ & $1.1(6.6)$ & $0.7(2.7)$ & 0.705 \\
\hline \multicolumn{5}{|c|}{ Reduction in missed work/school days due to axSpA treatment in past 3 months } \\
\hline $\begin{array}{l}\text { Reported missing fewer days due to axSpA } \\
\text { treatment, } n(\%)\end{array}$ & $58(49.6)$ & $44(62.9)$ & $14(29.8)$ & $<0.001^{*}$ \\
\hline $\begin{array}{l}\text { Estimated number of fewer days missed, mean } \\
(\mathrm{SD})^{\mathrm{f}}\end{array}$ & $9.9(17.6)$ & $8.6(15.9)$ & $14.1(22.3)$ & 0.305 \\
\hline
\end{tabular}

$W P A I$ Work Productivity and Activity Impairment questionnaire

*Statistically significant at $p<0.05$; $t$-tests were performed for continuous variables and Chi-square tests for categorical variables. $p$-values are nominal in nature and should be interpreted in an exploratory manner

a-month recall period

${ }^{\mathrm{b}}$ Average days missed over a 3-month period

${ }^{\text {c}}$ Percentage impairment on productivity while working due to axSpA over 3-month period

${ }^{\mathrm{d}}$ Percentage impairment on daily activities outside of work due to axSpA over 3-month period

eParticipants who indicated missing $\geq 1$ day of work or school because of problems associated with their axSpA

fParticipants who reported that their axSpA treatment helped them avoid missing work/school

$(n=70)$ and participants not on a bDMARD

$(n=47)$. However, more participants on a

bDMARD reported that they missed fewer days of work due to their treatment $(44,62.9 \%)$ than participants not on a bDMARD $(14,29.8 \%$; $p<0.001$ ) (Table 3). 


\section{DISCUSSION}

This study, which examined the differences in a predominantly female cohort of axSpA patients who are either employed or not employed because of axSpA, found that not employed participants experienced a significantly longer wait between symptom onset and axSpA diagnosis than employed participants, had significantly poorer health outcomes, and more often reported comorbidities, such as fibromyalgia, than employed participants. The study did not find significant differences in employment rates between male and female participants. There were a few significant differences in demographic and clinical characteristics between the two groups, with male participants being older and more educated, while female participants more often reported having fibromyalgia, heel enthesitis, dactylitis, poorer BASDAI scores, and greater emotional distress.

This study found that not employed participants had worse health outcomes based on various PROMIS measures than their employed counterparts, regardless of whether or not they were on a bDMARD. The differing results in health outcomes indicate that disease activity and functionality are associated with employment status. Although this study is a cross-sectional study and as a result unable to study temporality, these results are consistent with findings from prior research, which found that decreased work productivity and lack of employment are correlated with worse disease activity and physical function $[6,9,14]$. Compared to employed participants, not employed participants also reported being older when they were first diagnosed and experienced a significantly greater length in time between symptom onset and diagnosis. We also found that younger age and younger age at diagnosis were positively correlated with employment. Prior research demonstrates that older age at diagnosis and longer delays in diagnosis may contribute to a reduction in employment and work productivity [6, 34-36]. Additionally, significantly more participants who were not employed reported having concomitant fibromyalgia than employed participants. This is not surprising, as results from previous studies have shown that axSpA patients with concomitant fibromyalgia have more disease activity, functional impairment, fatigue, pain, and poorer quality of life than patients without fibromyalgia [37, 38]. Studies have also found that high axSpA disease activity and widespread pain are associated with the development of fibromyalgia [39-41].

As described previously, unemployed participants whose current unemployment was not due to their axSpA were removed from the analysis; however it is still important to highlight that of all the unemployed participants who completed the survey, more than twothirds were not employed for reasons partially or entirely due to their axSpA. These findings are important to consider when discussing treatment goals with axSpA patients, especially considering treat-to-target approaches [42].

This study found no significant differences in workdays missed due to absenteeism or to the impact on presenteeism among employed participants on a bDMARD versus not on a bDMARD. Prior research has similarly demonstrated the varying impact bDMARD treatment has on work productivity. While clinical trial results from numerous studies have found reduction in sick leave and mean days of sick leave [19] and improved absenteeism, presenteeism, and work productivity 1-2 years into treatment [20-22], there have also been trials that demonstrated no significant difference in absenteeism between the intervention group and control during the study period $[15,16]$. The present cross-sectional study was not designed to test the impact of bDMARD therapy on work productivity, and we would expect that the most severely affected patients are more likely to be treated with a bDMARD. Thus, we expect confounding by disease severity to be the likely explanation for not observing a difference between participants treated or not treated with a bDMARD.

The findings of this study should be considered in light of several limitations. The use of a technology-based community that is primarily White and college-educated limits the generalizability of this study's findings. The study's sample is also predominantly female, more so 
than is typically observed with the axSpA patient population. This may be explained by the fact that women are typically more active online for disease information and support [43]. That being said, the proportion of female respondents in this study may help shed light on a population that is often understudied within this condition. BASDAI scores were higher than those seen in other registries [44], suggesting high axSpA disease activity, but it is possible that axSpA patients displeased with their treatment and care may have been more likely to participate in a survey on axSpA-related treatment, care, and impairment. Our findings are based on participants' self-reported diagnosis, treatment, symptoms, and experiences; the limitations of self-report include recall bias. Selfreport may have also resulted in underreporting due to lack of clinical knowledge. For example, $57 \%$ of participants reported having a positive HLA-B27 test, but 15\% of participants did not know if they had been tested for it. We tried to limit this gap in clinical understanding by adding context to many of the questions: heel enthesitis was described as "tenderness to pressure at the bottom or back of heel," dactylitis was described as "painful swelling of an entire finger or toe, usually just one or a few at a time," and uveitis/irisitis was described as "eye inflammation diagnosed by an eye doctor," as examples.

Participants' current and former type of work is unknown, preventing us from exploring differences in participants with jobs that require varying amounts of physical effort or prolonged sitting or standing. Moreover, most participants reported having ankylosing spondylitis as opposed to other forms of axSpA, thus further limiting the generalizability. However, we would note that all participants reported being diagnosed by a rheumatologist, and more than $85 \%$ of participants have ever been on a DMARD, either biologic or conventional synthetic, increasing the face validity of the selfreported axSpA diagnosis.

\section{CONCLUSIONS}

This study aimed to characterize employment, work productivity, and bDMARD treatment in a predominantly female population of axSpA patients in a real-world setting. Participants experienced high levels of unemployment that they attributed partially or entirely to axSpA. Employed participants reported frequent challenges with absenteeism and productivity due to axSpA symptoms. Among participants on a bDMARD, employed participants had better health outcomes (BASDAI, pain interference, physical function, sleep disturbance, self-rated health, and emotional distress) than participants who were not employed. Not employed participants more frequenty reported comorbidities, such as fibromyalgia, which may have also contributed to their worse health outcomes. Characterizing work impairments due to axSpA and other patient-oriented outcomes is important for understanding the needs of this patient population. This information may guide strategies for treating axSpA and managing the diverse impacts of axSpA on patients' lives.

\section{ACKNOWLEDGEMENTS}

The authors wish to thank Jennifer Walker for her assistance in study conceptualization and design. The authors also wish to thank Laura Stradford for her help in planning and implementing the study, and participants of ArthritisPower registry for their time and willingness to participate in this study.

Funding. This study and journal's Rapid Service Fee was sponsored by Eli Lilly and Company. This work was partially supported through a Patient-Centered Outcomes Research Institute (PCORI) award (PPRN-1306-04811). All statements in this manuscript, including its findings and conclusions, are solely those of the authors and do not necessarily represent the views of the PCORI, its Board of Governors, or Methodology Committee. 
Authorship. All named authors meet the International Committee of Medical Journal Editors (ICMJE) criteria for authorship for this article, take responsibility for the integrity of the work as a whole, and have given their approval for this version to be published.

Author Contributions. Conception of the work: Kelly Gavigan (KG), W Benjamin Nowell (WBN), Theresa Hunter (TH), William N Malatestinic (WNM), Jessica A Walsh (JAW). Design of the work: KG, WBN, TH, Jeffrey $\mathrm{R}$ Curtis (JRC), WMN, Rebecca J. Bolce (RJB), Jeffrey R. Lisse (JRL), JAW. Acquisition of data for the work: KG, WBN. Analysis of data for the work: KG, WBN. Interpretation of data for the work: KG, WBN, TH, JRC, WMN, RJB, JRL, JAW. Drafting of manuscript: KG, WBN, TH, JAW. Critical revision of manuscript for important intellectual content: KG, WBN, TH, JRC, WMN, RJB, JRL, JAW.

Prior Presentation. This manuscript is based on work that was previously published as an abstract at the American College of Rheumatology conference in November 2020.

Disclosures. Kelly Gavigan has no personal conflicts of interests to disclose and is an employee of the Global Healthy Living Foundation (GHLF). William B Nowell is the Principal Investigator on grants/contracts from AbbVie, Eli Lilly and Company, and PCORI, and an employee of the GHLF. GHLF receives grants, sponsorships, and contracts from pharmaceutical manufacturers and private foundations. A full list of GHLF funders is publicly available here: https://www.ghlf.org/our-partners/.

Theresa Hunter, William Malatestinic, Rebecca Bolce, and Jeffrey Lisse are employees and shareholders of Eli Lilly and Company. Jeffrey R Curtis receives grants and personal fees from AbbVie, Amgen, BMS, Corrona, Eli Lilly and Company, Janssen, Myriad, Pfizer, Regeneron, Roche, and UCB, and receives personal fees from Gilead, Novartis, and Samsung. Jessica A Walsh receives grants from AbbVie, Merck, and Pfizer, and has received personal fees from AbbVie, Amgen, Eli Lilly and Company, Janssen, Novartis, Pfizer, and UCB.
Compliance with Ethics Guidelines. This study has received an exempt determination from Advarra Institutional Review Board, stating that the study is exempt from IRB oversight. This study was performed in accordance with the Helsinki Declaration of 1964, and its later amendments. All subjects provide informed consent to participate in the study.

Data Availability. The datasets generated during and/or analyzed during the current study are available from the corresponding author on reasonable request.

Open Access. This article is licensed under a Creative Commons Attribution-NonCommercial 4.0 International License, which permits any non-commercial use, sharing, adaptation, distribution and reproduction in any medium or format, as long as you give appropriate credit to the original author(s) and the source, provide a link to the Creative Commons licence, and indicate if changes were made. The images or other third party material in this article are included in the article's Creative Commons licence, unless indicated otherwise in a credit line to the material. If material is not included in the article's Creative Commons licence and your intended use is not permitted by statutory regulation or exceeds the permitted use, you will need to obtain permission directly from the copyright holder. To view a copy of this licence, visit http://creativecommons.org/licenses/by$\mathrm{nc} / 4.0 /$.

\section{REFERENCES}

1. Danve A, Deodhar A. Axial spondyloarthritis in the USA: diagnostic challenges and missed opportunities. Clin Rheumatol. 2019;38(3):625-34.

2. Reveille JD, Witter JP, Weisman MH. Prevalence of axial spondylarthritis in the United States: estimates from a cross-sectional survey. Arthritis Care Res (Hoboken). 2012;64(6):905-10.

3. Sieper J, Braun J, Dougados M, Baeten D. Axial spondyloarthritis. Nat Rev Dis Prim. 2015;1(1): 15013. 
4. Sieper J, van der Heijde D, Landewé R, et al. New criteria for inflammatory back pain in patients with chronic back pain: a real patient exercise by experts from the Assessment of SpondyloArthritis international Society (ASAS). Ann Rheum Dis. 2009;68(6): 784-8.

5. Taurog JD, Chhabra A, Colbert RA. Ankylosing spondylitis and axial spondyloarthritis. N Engl J Med. 2016;374(26):2563-74.

6. Boonen A, Chorus A, Miedema H, et al. Withdrawal from labour force due to work disability in patients with ankylosing spondylitis. Ann Rheum Dis. 2001;60(11):1033-9.

7. Marengo MF, Schneeberger EE, Citera G, Cocco JA. Work status among patients with ankylosing spondylitis in Argentina. J Clin Rheumatol. 2008;14(5):273-7.

8. Mau W, Listing J, Huscher D, Zeidler H, Zink A. Employment across chronic inflammatory rheumatic diseases and comparison with the general population. J Rheumatol. 2005;32(4):721-8.

9. de Hooge M, Ramonda R, Lorenzin M, et al. Work productivity is associated with disease activity and functional ability in Italian patients with early axial spondyloarthritis: an observational study from the SPACE cohort. Arthritis Res Ther. 2016;18(1):265.

10. Boonen A, Brinkhuizen $T$, Landewé $R$, van der Heijde D, Severens JL. Impact of ankylosing spondylitis on sick leave, presenteeism and unpaid productivity, and estimation of the societal cost. Ann Rheum Dis. 2010;69(6):1123.

11. Boonen A, Boone C, Albert A, Mielants H. Understanding limitations in at-work productivity in patients with active ankylosing spondylitis: the role of work-related contextual factors. J Rheumatol. 2015;42(1):93.

12. Jacobs P, Bissonnette R, Guenther LC. Socioeconomic burden of immune-mediated inflammatory diseases - focusing on work productivity and disability. J Rheumatol. 2011;88:55-61.

13. Kobelt G, Andlin-Sobocki P, Maksymowych WP. Costs and quality of life of patients with ankylosing spondylitis in Canada. J Rheumatol. 2006;33(2): 289-95.

14. Maksymowych WP, Gooch KL, Wong RL, Kupper $\mathrm{H}$, van der Heijde D. Impact of age, sex, physical function, health-related quality of life, and treatment with adalimumab on work status and work productivity of patients with ankylosing spondylitis. J Rheumatol. 2010;37(2):385-92.
15. van der Heijde D, Han C, DeVlam K, et al. Infliximab improves productivity and reduces workday loss in patients with ankylosing spondylitis: results from a randomized, placebo-controlled trial. Arthritis Rheum. 2006;55(4):569-74.

16. Dougados M, Tsai WC, Saaibi DL, et al. Evaluation of health outcomes with etanercept treatment in patients with early nonradiographic axial spondyloarthritis. J Rheumatol. 2015;42(10):1835-41.

17. Shim J, Jones GT, Pathan EMI, Macfarlane GJ. Impact of biological therapy on work outcomes in patients with axial spondyloarthritis: results from the British Society for Rheumatology Biologics Register (BSRBR-AS) and meta-analysis. Ann Rheum Dis. 2018;77(11):1578-84.

18. Keat AC, Gaffney K, Gilbert AK, Harris C, Leeder J. Influence of biologic therapy on return to work in people with work disability due to ankylosing spondylitis. Rheumatology. 2008;47(4):481-3.

19. Listing J, Brandt J, Rudwaleit M, Zink A, Sieper J, Braun J. Impact of anti-tumour necrosis factor alpha treatment on admissions to hospital and days of sick leave in patients with ankylosing spondylitis. Ann Rheum Dis. 2004;63(12):1670-2.

20. van der Heijde D, Braun J, Rudwaleit M, Purcaru O, Kavanaugh AF. Improvements in workplace and household productivity with certolizumab pegol treatment in axial spondyloarthritis: results to week 96 of a phase III study. RMD Open. 2018;4(1): e000659.

21. van der Heijde D, Joshi A, Pangan AL, et al. ASAS40 and ASDAS clinical responses in the ABILITY-1 clinical trial translate to meaningful improvements in physical function, health-related quality of life and work productivity in patients with non-radiographic axial spondyloarthritis. Rheumatology. 2016;55(1):80-8.

22. van der Heijde D, Deodhar A, Braun J, et al. The effect of golimumab therapy on disease activity and health-related quality of life in patients with ankylosing spondylitis: 2-year results of the GO-RAISE trial. J Rheumatol. 2014;41(6):1095-103.

23. Rusman $\mathrm{T}$, van Vollenhoven $\mathrm{RF}$, van der HorstBruinsma IE. Gender differences in axial spondyloarthritis: women are not so lucky. Curr Rheumatol Rep. 2018;20(6):35.

24. Baumberger H, Khan M. SAT0417|Gradual progressive change to equal prevalence of ankylosing spondylitis among males and females in Switzerland: data from the Swiss Ankylosing Spondylitis Society (SVMB). Ann Rheum Dis. 2017;76(Suppl 2): 929. 
25. van der Horst-Bruinsma IE, Zack DJ, Szumski A, Koenig AS. Female patients with ankylosing spondylitis: analysis of the impact of gender across treatment studies. Ann Rheum Dis. 2013;72(7): 1221-4.

26. Webers C, Essers I, Ramiro S, Stolwijk C, Landewé R, van der Heijde D, et al. Gender-attributable differences in outcome of ankylosing spondylitis: longterm results from the Outcome in Ankylosing Spondylitis International Study. Rheumatology. 2016;55(3):419-28.

27. Kristensen LE, Karlsson JA, Englund M, Petersson IF, Saxne T, Geborek P. Presence of peripheral arthritis and male sex predicting continuation of anti-tumor necrosis factor therapy in ankylosing spondylitis: an observational prospective cohort study from the South Swedish Arthritis Treatment Group Register. Arthritis Care Res. 2010;62(10):1362-9.

28. Nowell WB, Curtis D, Thai M, Wiedmeyer C, Gavigan $\mathrm{K}$, Venkatachalam S, et al. Digital interventions to build a patient registry for rheumatology research. Rheum Dis Clin N Am. 2019;45(2): 173-86.

29. Nowell WB, Curtis JR, Crow-Hercher R. Patient governance in a patient-powered research network for adult rheumatologic conditions. Med Care. 2018;56 Suppl 10 Suppl 1(10 Suppl 1):S16-21.

30. Garrett S, Jenkinson T, Kennedy LG, Whitelock H, Gaisford P, Calin A. A new approach to defining disease status in ankylosing spondylitis: the Bath Ankylosing Spondylitis Disease Activity Index. J Rheumatol. 1994;21(12):2286-91.

31. Broderick JE, DeWitt EM, Rothrock N, Crane PK, Forrest CB. Advances in patient-reported outcomes: the NIH PROMIS ${ }^{\circledR}$ measures. EGEMs (Wash DC). 2013;1(1):1015.

32. Magrey MN, Danve AS, Ermann J, Walsh JA. Recognizing axial spondyloarthritis: a guide for primary care. Mayo Clin Proc. 2020;95(11):2499-508.

33. Reilly MC, Zbrozek AS, Dukes EM. The validity and reproducibility of a work productivity and activity impairment instrument. Pharmacoeconomics. 1993;4(5):353-65.

34. Seo MR, Baek HL, Yoon HH, et al. Delayed diagnosis is linked to worse outcomes and unfavourable treatment responses in patients with axial spondyloarthritis. Clin Rheumatol. 2015;34(8):1397-405.
35. Gunasekera W, Shaddick G, Jobling A, Smith A, Sengupta R. AB0735 Diagnostic delay worsens mobility and work disability in ankylosing spondylitis. Ann Rheum Dis. 2014;73(Suppl 2): 1046.

36. Cakar E, Taskaynatan MA, Dincer U, Kiralp MZ, Durmus O, Ozgül A. Work disability in ankylosing spondylitis: differences among working and workdisabled patients. Clin Rheumatol. 2009;28(11): 1309-14.

37. Zhao SS, Duffield SJ, Goodson NJ. The prevalence and impact of comorbid fibromyalgia in inflammatory arthritis. Best Pract Res Clin Rheumatol. 2019;33(3):101423.

38. Son SM, Kim DS, Lee JS. Fibromyalgia in axial spondyloarthritis: a meta-analysis. J Clin Rheumatol. 2022;28(1):e222-7.

39. Provan SA, Dean LE, Jones GT, Macfarlane GJ. The changing states of fibromyalgia in patients with axial spondyloarthritis: results from the British Society of Rheumatology Biologics Register for Ankylosing Spondylitis. Rheumatology. 2021;60(9): 4121-9.

40. Duffield SJ, Miller N, Zhao S, Goodson NJ. Concomitant fibromyalgia complicating chronic inflammatory arthritis: a systematic review and meta-analysis. Rheumatology. 2018;57(8):1453-60.

41. Macfarlane GJ, Pathan E, Siebert S, et al. AxSpA patients who also meet criteria for fibromyalgia: identifying distinct patient clusters using data from a UK national register (BSRBR-AS). BMC Rheumatol. 2019;3(1):19.

42. Smolen JS, Braun J, Dougados M, et al. Treating spondyloarthritis, including ankylosing spondylitis and psoriatic arthritis, to target: recommendations of an international task force. Ann Rheum Dis. 2014;73(1):6-16.

43. Cooksey R, Brophy S, Husain MJ, Irvine E, Davies H, Siebert S. The information needs of people living with ankylosing spondylitis: a questionnaire survey. BMC Musculoskelet Disord. 2012;13:243.

44. Mease PJ, Heijde DVD, Karki C, et al. Characterization of patients with ankylosing spondylitis and nonradiographic axial spondyloarthritis in the USbased Corrona Registry. Arthritis Care Res. 2018;70(11):1661-70. 